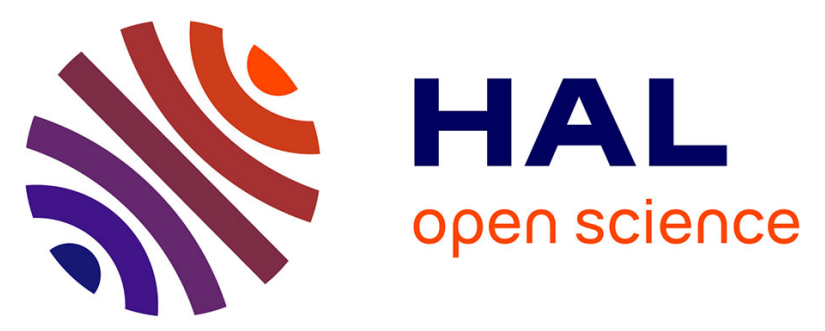

\title{
Comparative Study of Transient Disturbances Impact on 2G and 4G Telecommunication Systems in a Railway Context
}

Mohammed Raouf Kousri, Virginie Deniau, Jean Rioult, Grecia Romero, Eric Pierre Simon

\section{To cite this version:}

Mohammed Raouf Kousri, Virginie Deniau, Jean Rioult, Grecia Romero, Eric Pierre Simon. Comparative Study of Transient Disturbances Impact on $2 \mathrm{G}$ and $4 \mathrm{G}$ Telecommunication Systems in a Railway Context. URSI GASS 2017 - 32nd International Union of Radio Science General Assembly \& Scientific Symposium, Aug 2017, Montreal, Canada. 4p. hal-01662738

\section{HAL Id: hal-01662738 https://hal.science/hal-01662738}

Submitted on 13 Dec 2017

HAL is a multi-disciplinary open access archive for the deposit and dissemination of scientific research documents, whether they are published or not. The documents may come from teaching and research institutions in France or abroad, or from public or private research centers.
L'archive ouverte pluridisciplinaire HAL, est destinée au dépôt et à la diffusion de documents scientifiques de niveau recherche, publiés ou non, émanant des établissements d'enseignement et de recherche français ou étrangers, des laboratoires publics ou privés. 


\title{
Comparative Study of Transient Disturbances Impact on 2G and 4G Telecommunication Systems in a Railway Context
}

\author{
Mohamed Raouf Kousri ${ }^{(1)}$, Virginie Deniau*(1) Jean Rioult $^{(1)}$, Grecia Romero $^{(2)}$ and Eric Pierre Simon ${ }^{(2)}$ \\ (1) COSYS/LEOST, IFSTTAR, Villeneuve d'Ascq, France \\ (2) University of Lille, Villeneuve d'Ascq, France
}

\begin{abstract}
For reliability and safety purposes, the signaling systems in the railway domain are continuously evolving. Today, in Europe, the GSM-R is used as a part of the European Railway Traffic Management System (ERTMS) and the transmission of signaling information is increasingly ensured by the GSM-R. With the evolution of the telecommunication systems, new technologies using OFDM techniques, such as LTE could be exploited for railway applications. However, knowing that the railway electromagnetic environment is very hostile and rich in terms of electromagnetic interferences, studies need to be carried out to anticipate the EMC issues that could impact LTE performances. In this paper, we propose a comparative study between GSM$\mathrm{R}$ and LTE communications in the presence of transient electromagnetic interferences, generally present on board trains.
\end{abstract}

\section{Introduction}

The railway signaling systems are increasingly relying on new telecommunication technologies. For example, in Europe, the ERTMS (European Railway Traffic Management System) was created to harmonize signaling protocols between different countries. Based on the same principle as the public GSM (Global System for Mobile), the GSM-R (GSM for Railway applications) represents a main part of the ERTMS [1]. Indeed, it guarantees a permanent radio communication between trains and control centers, allowing the exchange of signaling information. With the continuous evolution of the telecommunication system, the $2 \mathrm{G}$ technology used by the GSM-R may be progressively replaced by future or more recent technologies using Orthogonal Frequency Division Multiplexing(OFDM) techniques. As illustration, LTE (Long Term Evolution) communication system which uses OFDM technique allows us to reach a theoretical bit rate up to $300 \mathrm{Mbit} / \mathrm{s}$, and to have a better robustness against electromagnetic disturbances [2].

Though the railway electromagnetic environment is rich in terms of electromagnetic interferences (EMI) and especially transient disturbances like those emitted by pantograph and catenary sliding contact. This type of EMI have wide frequency band coverage. They also could reach a high frequency of occurrence especially in the case of high speed trains [3]. All these features make this kind of EMI able to disturb a large panel of telecommunication and signaling systems used in railways.

While different studies had been carried out to assess the impact of transient disturbances on the GSM-R operation [4], studies on the impact of the same type of EMI on the LTE are still not existent. For this purpose, we propose in this paper a preliminary study that compares the behavior of the GSM-R and LTE in the presence of a repetitive transient interference. A test bench had been mounted in order to carry out this study and we chose as comparison parameter the EVM (Error Vector Magnitude). This parameter allows the evaluation of a digital telecommunication system performance by quantifying the deviation of the received constellation points from their ideal positions.

After this introduction, the next part of this paper gives a brief presentation of the two studied telecommunication systems, the GSM-R and LTE. Afterwards, the test bench used in this study and the results will be presented. Finally, a conclusion will be given.

\section{GSM-R and LTE Technical Characteris- tics}

\subsection{GSM-R}

The GSM-R, based on the GSM communication standard, is a wireless railway signaling system allowing voice and data transmissions between trains and railway control centers. This communication is ensured using Base Transceiver Stations (BTS) located alongside railway lines, and on-board mobile station connected to an antenna fixed on the roof of the trains. The frequency bands allocated to GSM-R in Europe are $876-880 \mathrm{MHz}$ for the uplink and 921-925 MHz for the downlink. Each band is divided into 20 channels of $200 \mathrm{kHz}$. The modulation used is the Gaussian Minimum Shift Keying (GMSK), whose advantage is the reduction of the sideband power, minimizing thus the overflowing between the $200 \mathrm{kHz}$ channels. Figure 1 provides a time-frequency representation of a GSM-R signal modulated at $924.8 \mathrm{MHz}$. The frequency shifting of the 


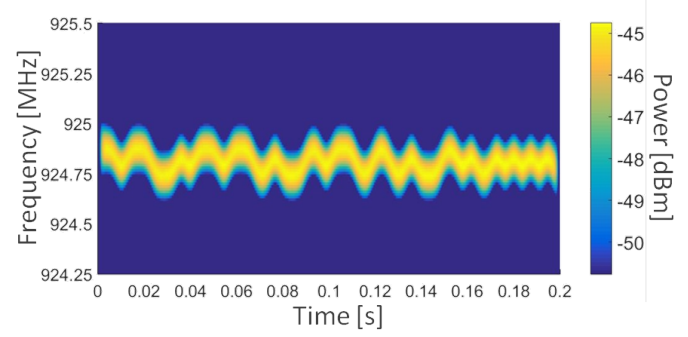

Figure 1. Time-frequency representation of a GSM-R signal.

modulated GSM-R signal within the $200 \mathrm{kHz}$ channel can clearly be seen in this figure.

Using the Time Division Multiple Access (TDMA) technique, every GSM-R channel can be shared simultaneously by up to 8 users, each one of them occupies a $577 \mu$ s time slot interval of a $4.615 \mathrm{~ms}$ periodic TDMA frame. The duration of an elementary data bit is equal to $3.7 \mu$ s [5].

According to previous studies [6], it is known that GSM-R is vulnerable to different types of EMI, especially the transient interferences. Indeed, GSM-R antennas are located on the roof of the trains, they are thus directly exposed to the sliding contact between pantograph and catenary which is a source of recurrent transient disturbances. Their impact on the GSM-R communications quality mainly depends on the power level and the occurrence intervals of the transient disturbances. Knowing that communication systems using OFDM, could be progressively used for railway applications, similar studies must be carried out for communication using OFDM techniques. Therefore, we analysed the impact of such transient disturbances on LTE communications in comparison with their impact on GSM-R communications.

\subsection{LTE}

Long Term Evolution (LTE) is a radio communication system considered as a $4 \mathrm{G}$ communication technology. It uses OFDM as an encoding technique which permits us to encode data on multiple carrier frequency within the allocated frequency band. It is known for its spectral efficiency due to its orthogonal sub-carriers [7].

LTE works with adaptable bandwidth channels going from $1.4 \mathrm{MHz}$ to $20 \mathrm{MHz}$, providing peak downloading rates at $300 \mathrm{Mbit} / \mathrm{s}$. LTE supports both Frequency Division Duplexing (FDD) by allowing two different channels for uplink and downlink, and Time Division Duplexing where uplink and downlink share the same frequency channel.

The LTE frequency bands are used simultaneously by different users, thus, these bands are divided into sub-carriers which are dynamically allocated to users depending on their needs. In order to guarantee this dynamic allocation, LTE splits the band in the time and frequency domain into elementary elements called resource elements, which occupy $15 \mathrm{kHz}$ (one sub-carrier) and last $66 \mu \mathrm{s}$. These resource elements are regrouped into Resource blocks, composed of 12 sub-carriers $(180 \mathrm{kHz})$ and 7 OFDM symbols of $66 \mu \mathrm{s}$, $(0.5 \mathrm{~ms})$. Two consecutive resource blocks constitute a subframe of $1 \mathrm{~ms}$ [8].

\section{Experimentation and results}

In order to compare the performances of GSM-R and LTE in the presence of transient disturbances representative of those observed on board trains, a test bench was mounted in the EMC laboratory of IFSTTAR.

\subsection{Test Bench}

The test bench used in this study is presented in the diagram Figure 2 and it is composed of 3 main parts:

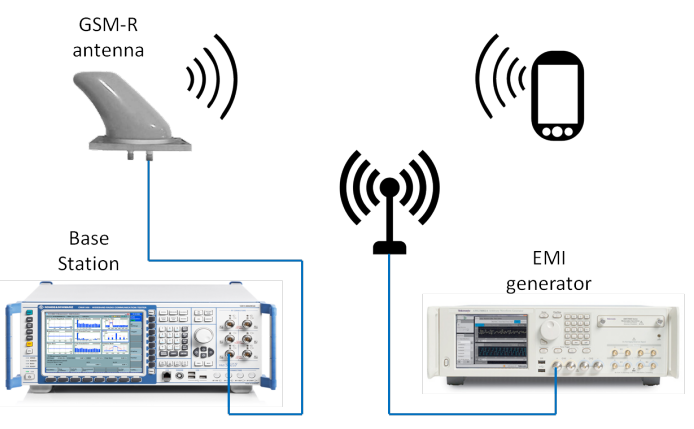

Figure 2. Diagram of the test bench used.

Base station emulator The Rohde \& Schwarz CMW 500 is a radio communication tester, it is used in order to emulate and test the GSM-R and the LTE networks. The CMW 500 is connected to a GSM-R antenna identical to those used by some train companies in Europe.

Mobile station A $2 \mathrm{G}$ and $4 \mathrm{G}$ equipped smart phone is used in order to establish a radio communication with the CMW 500. As the used smart phone is not adapted to railway applications frequency bands, the emulated GSM-R and LTE network are emitted in the public GSM $900 \mathrm{MHz}$ frequency band.

EMI generator The Tektronix Arbitrary Waveform Generator (AWG) 70001 is used to generate the transient disturbance through a wide band antenna. This equipment allows us to control the time interval between 2 successive transient disturbances.

\subsection{Testing Procedure}

The test process is conducted as follows: first, the tested network is configured on the CMW 500. The same center frequencies were used for GSM-R or LTE: $882.5 \mathrm{MHz}$ 
for the uplink and 927.5 MHz for the downlink, the LTE network is thus in the FDD mode. Also, the power level is equivalent for both networks. While the GSM-R uses $200 \mathrm{kHz}$ channels, the narrowest LTE channel bandwidth is $1.4 \mathrm{MHz}$. The LTE network is then configured with this 1.4 MHz channel bandwidth and with a QPSK modulation for both uplink and downlink.

The next step of the test requires to connect the mobile station. Using a test SIM card and a smart phone, this latter is registered on the network. A communication is then established, during which the CMW 500 performs different types of measurements and gives different information regarding the quality of the received signals, and thus the uplink channel. For this reason, we decided that the used interference must cover the uplink frequency band.

Finally, the last step of the testing procedure is to create the transient disturbance and generate it using the AWG. The EMI used is synthesized by adding several sine functions with frequency going from $F_{1}=880 \mathrm{MHz}$ to $F_{2}=885 \mathrm{MHz}$ during a short amount of time as described in Equation 1.

$$
\operatorname{Tr}(t)=A \sum_{f=F_{1}}^{F_{2}} \cos (2 \pi f t)
$$

The duration (D) of the created disturbance is $1 \mu \mathrm{s}$. The transient disturbance is shorter than a data bit duration in the case of GSM-R (3.7 $\mu \mathrm{s})$ and a resource element duration in the case of LTE $(66 \mu \mathrm{s})$. Once the transient disturbance is created with Matlab, it is loaded in the AWG in order to be generated with an adjustable time interval (T) going from $100 \mu$ s to $1 \mu \mathrm{s}$. The spectrum of this transient interference signal and its time domain representation are presented in Figure 3. In this figure, the spectrum is measured with a $200 \mathrm{kHz}$ resolution bandwidth (RBW), which is equivalent to the GSM-R frequency resolution. The SIR is about $25 \mathrm{~dB}$ for the GSM-R. However, LTE receiver uses different values of RBW (1.4 MHz is the channel bandwidth and $15 \mathrm{kHz}$ is the sub-carriers spacing). Thus, and since we are dealing with wide band interferences, the interference power at the LTE receiver level would be different from that perceived by the GSM-R receiver. The Signal to Interference Ratio (SIR) is chosen in a way that the communication quality is impacted but without causing a disconnection between the base station and the mobile station. Figure 4 shows the spectra of GSM-R and LTE communications in the presence of the transient interference signal.

The procedure described above is repeated for both networks. The quality of the communication is measured with the CMW 500 each time the transient apparition rate changes. The results for both communication systems are finally compared.

\section{Results and interpretation}

The CMW 500 can provide several types of information on the quality of the received signals. As it is not possible

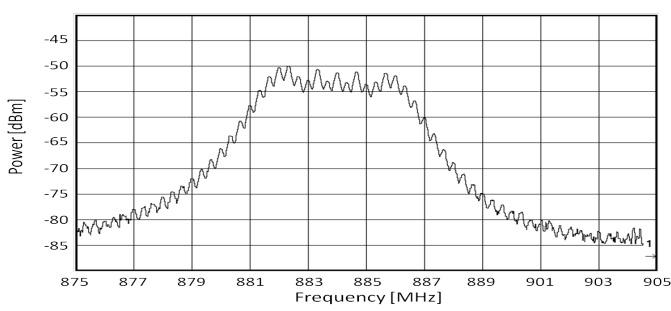

(a) Spectrum

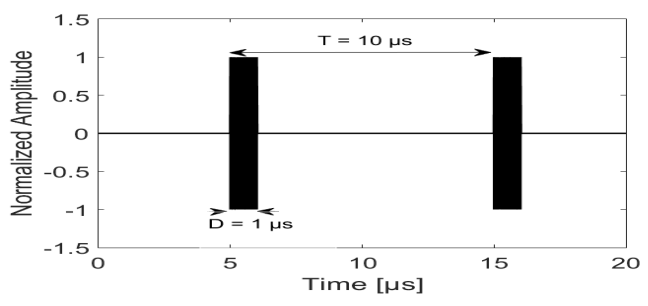

(b) Time domain represtation.

Figure 3. Spectrum and time domain representation of the interference applied.

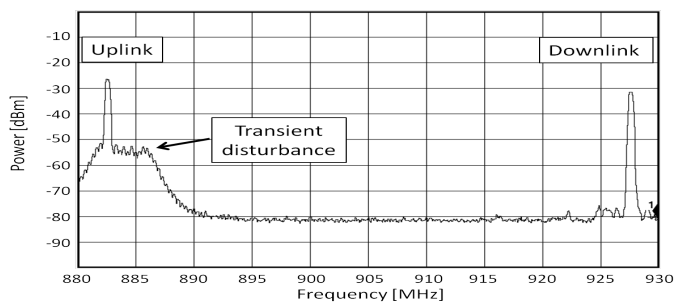

(a) GSM-R spectrum

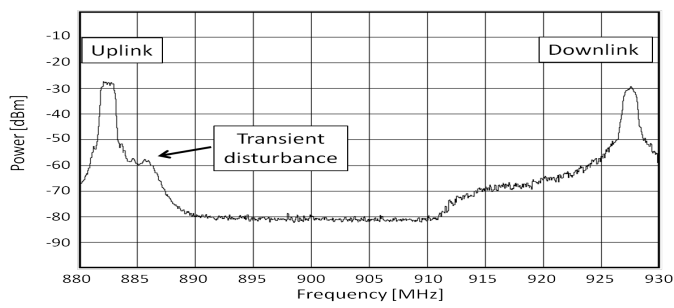

(b) LTE spectrum

Figure 4. Spectra of used GSM-R and LTE networks in presence of repeated transient interferences.

to compare the Bit Error Rate (BER) of both communication systems, due to the difference of their modulation and coding techniques, the use of the Error Vector Magnitude (EVM) was preferred for this preliminary study.

The EVM is a commonly used parameter to assess the robustness of a digital radio communication by measuring the deviation of the constellation points. Indeed, for a digital modulated signal, the symbols can be represented in the InPhase and Quadrature-Phase (IQ) representation. In theory, each symbol corresponds to a precise location in this plan, and all these positions constitute the reference constellation. At the reception, the received constellation points are compared to their ideal position in order to demodulate the signal. However, due to the EMI presence, the received 
constellation points can deviate from their ideal locations. The EVM is a percentage of this deviation with respect to the ideal locations, and generally the RMS of the EVM is used, corresponding to the normalized variance of the error [9].

Using the CMW 500, the $\mathrm{EVM}_{r m s}$ is measured for each value of time interval $\mathrm{T}$. The measurement is performed during 10 seconds for each $\mathrm{T}$ value, in order to obtain the average and the maximum values of the $\mathrm{EVM}_{r m s}$. The results are given in Figure 5.

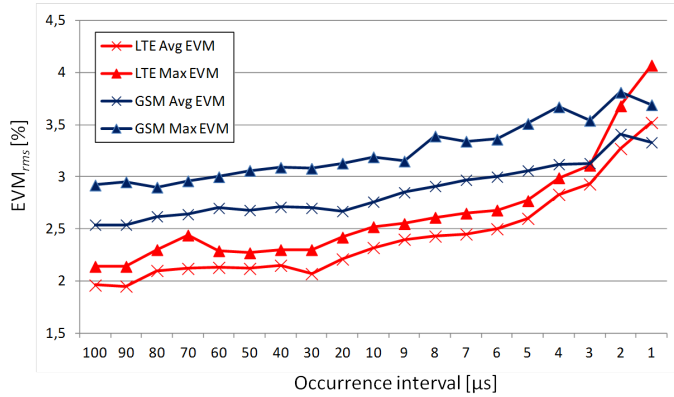

Figure 5. Average and maximum $\mathrm{EVM}_{r m s}$ of GSM-R and LTE communications for different interval of occurrence of the transient disturbance.

As shown in Figure 5, the $\mathrm{EVM}_{r m s}$ average and maximum values increase with the decrease of the time interval $\mathrm{T}$ and the evolution of the EVM is progressive. Between $100 \mu \mathrm{s}$ and $3 \mu \mathrm{s}$, LTE seems to be more robust than GSM-R. The value of its $\mathrm{EVM}_{r m s}$ is up to $1 \%$ less than the GSM-R EVM. Nevertheless, starting from $3 \mu$ s to $1 \mu$ s, LTE begins to be more vulnerable to the transient disturbance. According to a previous research work [3], the time intervals between 2 successive transients in the railway domain are mainly inferior to $17 \mu \mathrm{s}$. However, the tests were performed with a relatively high SIR. Thus, supplementary analysis have to be performed with different SIR values in order to verify if the observations coming the comparisons are still available for higher interference powers and to correctly understand the behavior of LTE and OFDM systems under these circumstances.

\section{Conclusion}

In this paper, we proposed a comparative study of the GSM$\mathrm{R}$ and LTE communications in the presence of transient interferences. Indeed, knowing that OFDM systems, such as LTE could be progressively employed for railway applications, their robustness against recurrent transient disturbances present in the railway environment must be tested and compared. After introducing the two different communication systems, the test bench used in this study was presented, then, the results of the comparison were given.

According to this comparison based on the EVM measurement, the LTE seems to be more robust than GSM-R for interval of repetition superior to $3 \mu \mathrm{s}$. For interval of repetition inferior to $3 \mu \mathrm{s}$, the LTE begins to be more vulnerable. Thus, more works need to be carried out to understand the reason of this vulnerability and to check if the observations are still available for different Signal to Interference Ratio. Moreover, knowing that the channel bandwidth of the LTE can vary, supplementary test configurations will be tested using different LTE channel bandwidth.

\section{Acknowledgments}

This works has been carried out in the framework of The ELSAT2020 project which is co-financed by the European Union with the European Regional Development Fund, the French state and the Hauts de France Region Council.

\section{References}

[1] M. Palumbo, "The ERTMS signaling system," www.railwaysignalling.eu,27, August 2014.

[2] C. M. R. Shahriar, "Resilient Waveform Design for OFDM-MIMO Communication Systems - PhD Dissertation Submitted to the Faculty of Virginia Polytechnic Institute," 11, September 2015.

[3] N. Ben Slimen, V. Deniau, J. Rioult, S. Dudoyer and S. Baranowski "Statistical characterisation of the EM interferences acting on GSM-R antennas fixed above moving trains," Eur. Phys. J. Appl. Phys., Volume 48, 21202, 2009.

[4] M. R. Kousri, V. Deniau, M. Heddebaut and S. Baranowski, "Evaluating Electromagnetic Railway Environment Using adaptive Time-Frequency Analysis," International Journal of Engineering and Technical Research (IJETR), Volume 4 , Issue 3, March 2016.

[5] P. S. Cannon, "Digital cellular telecommunications system (Phase 2+), Physical layer on the radio path, General description," ETSI Std., 2012.

[6] M. Pous,M. Azpurua and F. Silva, "Measurement and Evaluation Techniques to Estimate the Degradation Produced by the Radiated Transients Interference to the GSM System," in Electromagnetic Compatibility, IEEE Transactions on, $\mathrm{n}^{\circ} 199,2015$.

[7] F. Zaarour, "Channel Estimation Algorithms for OFDM in Interference Scenarios - PhD Dissertation Submitted to the University of Lille1, Sciences and Technologies," 27, November 2015.

[8] ETSI, "LTE; Evolved Universal Terrestrial Radio Access (E-UTRA); Physical channels and modulation," 3GPP TS 36.211 version 10.0.0 Release 10, 2011.

[9] M. D. McKinley, K. A. Remley, M. Myslinski, J. S. Kenney, D. Schreurs and B. Nauwelaers, "EVM Calculation for Broadband Modulated Signals," 64th ARFTG Conf. Dig., Orlando, FL, pp. 45-52, Dec. 2004. 